\title{
Papers
}

\section{The function of criticism}

\author{
RAANAN GILLON
}

Matthew Arnold once wrote an essay on "the function of criticism." I think we in medicine can learn something from Arnold, and I have borrowed his title as an excuse to analyse, in this quasiphilosophical John Locke Lecture, the function of criticism in the context of medical education and practice. I shall start with a brief account of what I mean by the words "criticism" and "function."

\section{Purpose of criticism}

In the broadest sense criticism is evaluation-in the words of the Oxford English Dictionary it is the passing of judgments on the qualities of something. Criticism need not, though it often is, be adverse criticism or fault finding, as the fact that it is perfectly ordinary to speak of adverse criticism indicates.

When I speak of the function of criticism I use the term function to mean not just the purpose of criticism but the way in which it fulfils its purpose: function is an active word stemming from the Latin verb fungor (I perform), and a function is "the special kind of activity proper to anything"; or "the mode of action by which it fulfils its purpose," again according to the $O E D$. Thus in considering the function of criticism I must consider not only its purpose or purposes but also the mode of action whereby it fulfils such purpose or purposes. I must consider, that is, how it works.

Matthew Arnold is his classic discussion was writing about literary criticism: but he offers as his "definition" of criticism, "a disinterested endeavour to learn and propagate the best that is known and thought in the world." I think it is fairly clear that this can serve neither as a definition of criticism, for it does not describe what criticism is, nor as an account of the function of criticism, for it gives no indication of how criticism works. With slight modifications, however, it seems to serve admirably as a unitary account of the purpose of criticism or at least of criticism at its best. Thus we may say, with some sacrifice of Arnoldian elegance, that the purpose of criticism is a disinterested endeavour to learn and or to propagate the best that is or may be known and thought in the world. The modifications are necessary, I believe, if we are to include in a single account of the purpose of criticism four quite different objectives. Learning the best that is known or thought, propagating the best that is known or thought, learning the best that may be known or thought, and propagating the best that may be known or thought. Thus the parent who criticises his child may be seeking to propagate the best, but he or she is not seeking to learn the best; the reader who privately criticises what he is reading may well seek to learn what is best without being interested in propagating it. And the critic of some established and accepted

Based on the John Locke Lecture given at the Society of Apothecaries on 20 February 1981.

Society for the Study of Medical Ethics, London WC1H 9LG RAANAN GILLON, MB, MRCP, editor, fournal of Medical Ethics body of thought may be seeking not so much to learn the best that is thought but the best that may be thought. He may, for instance, be seeking after truth.

As well as these noble aspects of the purpose of criticism there are, alas, other baser purposes and motives-including aggression, destructiveness, self-aggrandisement, and self-protection on the part of the critic. Sometimes such purposes may be avowed by the critic, if only to himself or to his analyst, but more often he does not even realise their existence, in which circumstances I suppose it would be more appropriate to speak of the motives for his criticism rather than of its purpose.

Another distinction worth considering is that between constructive and destructive criticism, both of which in common parlance seem to be used ambiguously. Thus sometimes when people speak of destructive criticism they mean simply any sort of adverse criticism; at other times they mean adverse criticism motivated by the critic's base motives. My own preferencethere seems to be no right and wrong about the matter-is for the latter. Destructive criticism is adverse criticism motivated not by a desire for the best but by such motives as aggression or self-aggrandisement or self-protection on the part of the critic. On the other hand, constructive criticism may well be adverse criticism, but it is motivated by Arnold's noble purpose (as modified)-that is, it is motivated by "a disinterested endeavour to learn and or to propagate the best that is or may be known or thought in the world." Henceforth that is how I shall use these terms.

\section{How criticism acts}

So much for the purpose of criticism; what about "the mode of action by which it fulfils its purpose"-its function? There are many different ways in which criticism works, but I think that they can all be seen to belong to one of two broad categories. Either criticism acts via the intellect-or it acts via the emotions. In practice, of course, it often acts through both simultaneously.

Criticism functioning through the intellectual mode does so as a result of intellectual activity both on the part of the critic and of his audience. Note, however, that there can be two sorts of intellectual activity involved; the first is not itself critical but merely entails acceptance of some standard as "the best that is or may be known or thought," and the critical endeavour is simply to learn or propagate correctly this standard. Thus the intellectual activity here is that of correct learning. In the second sort of intellectually acting criticism the standard itself is open to criticism. In this sort of essentially inquiring intellectual criticism the subject of criticism or the critic's audience must himself be able to criticise inquiringly. It is the latter which I shall argue is inadequately encouraged in medical educationinquiring intellectual criticism.

Criticism acting through the psychological mode works without the intervention of intellectual activity. We do not have to be thoroughgoing Freudians to accept that from our earliest childhood the need for approval and the fear of disapproval from 
important people such as parents, other authority figures, and social peer groups are powerful motives for accepting criticisms quite independently of any rational assessment of the criticisms themselves; so too we may accept, without too much controversy, I hope, the Freudian notion of a superego in which parental attitudes are incorporated (or "introjected") into the child's own personality and subsequently long influence his own attitudes and behaviour. It is presumably the combination of such factors that enables criticism by certain important people-sometimes now called role-model figures-to produce change without the intervention of any intellectual assessment of the criticism itself.

Having done some preliminary analysis of what I mean by criticism; of its purposes and motives; and of ways in which these purposes and motives may be fulfilled, let me now consider the function of criticism in the education and practice of the doctor. I shall as a literary conceit borrow Jaques's somewhat arbitrary taxonomy of human development ${ }^{2}$ to serve as a rough scaffolding for what follows.

As I have already suggested, criticism will begin to have its effect on the medical practice of our hypothetical doctor very early in his life-probably even while he is still mewling and puking in the nurse's or mother's arms, for even at this stage parents are criticising their infants-that is to say, they are judging, are they not, their unfortunate infant's qualities in a disinterested endeavour to propagate the best that is known or thought. Their criticism paradigmatically functions through the psychological mode because there is no intellectual mode yet available for it to function otherwise. Thus approved behaviour - for example, smiling and gurgling-well, contented gurgling at least-is likely to be rewarded by hugs and kisses and general emotional approbation, while disapproved behaviour-biting, screaming, and soiling, for instance-is likely to be punished either by the withholding of approbation, or more positively. As the infant learns to talk, to this basic emotionally acting form of criticism-essentially pleasure-pain conditioning-will be added criticism by reasoning.

\section{Criticism by reasoning}

And so next the whining schoolboy with his satchel and shining morning face creeping like snail unwillingly to school. With him, I suggest, the purpose of criticism remains the propagation of the best that is known or thought, and only towards the end of his school career will the critical objective of learning the best that may be known or thought become an important component of his education. It is an important objective because it is the only one that will stimulate a similar sort of critical ability in the child, and later the adult. And without the desire and capacity to learn the best that may be known and thought in the world there can be no intellectual progress. Merely learning the best that is known and thought in the world, while it is a necessary and entirely admirable objective in education, is not sufficient if intellectual stagnation is to be avoided.

Interestingly John Locke himself, whose letters entitled "Thoughts concerning education" were of considerable influence, even if this influence is overshadowed by his enormous effect on political and philosophical thought, urged that education pay less attention to rote learning inculcated by the rod and more attention to developing curiosity, questioning, and the powers of reasoning - and among the subjects he recommended for the school curriculum was ethics-not to mention dancing, music, and at least one manual skill. But I digress.

Eventually our whining schoolboy metamorphoses: he becomes the lover sighing like a furnace with a woeful ballad made to his mistress's eyebrow. As I have indicated, I am not in this lecture concerned with literary criticism, no matter how woeful the ballad. Let us assume, however, that our late adolescent is not only a lover but a medical student. In this context he will be subject to intensive criticism ranging over the whole spectrum that I have outlined. His teachers, I suggest, will be concerned primarily with inculcating the best that is known and thought rather than with the best that may be known and thought-thus inquisitive criticisms will not receive much emphasis; the sheer weight of facts and their intercorrelations that the medical student is obliged to memorise, the sheer effort that he must make to acquire technical skills, do not leave much time or energy for the exercise of other intellectual skills; moreover, in so far as intellectual inquiry is encouraged, it is a certain aspect of scientific endeavour that takes precedence. Let me expand.

We all know the Popperian model of scientific inquiry ${ }^{3}$; the scientist has an idea that he expresses as a hypothesis; the source of the idea, its relations with other ideas, are not important; what is important is to test the idea by scientific experiment and to attempt to falsify it; the more unsuccessful such experimental efforts to falsify the hypothesis are, the more weight we should give to it. Now in medical education what emphasis there is on intellectual inquiry is largely orientated to this scientific model; if a student comes up with a new idea or hypothesis, speculation about it tends to be discouraged and instead the student is encouraged to test it in appropriately controlled experiments, and especially, these days, to subject his results to appropriate statistical analysis. This encouragement of scientific method is admirable but it does tend to kill debate and argument. Moreover, it is encouraged to the almost total detriment of other forms of intellectual inquiry such as those of literature, philosophy, or politics-of the humanities in general. Here too the techniques of intellectual inquiry may involve hypotheses and attempts at falsification but the experiments are of a different sort, thought experiments rather than real experiments-based often on counterfactuals - what would happen if a, suppose b, imagine c. Central to such critical activities are argument and debate.

Unfortunately, argument and debate are positively detrimental to the main concerns of medical education, notably to the learning of facts and their intercorrelations and the acquisition of technical skills. The medical teacher's objectives are to make sure that the tasks laid down-assumed to be reflections of the best that is known or thought-are carried out properly and to achieve this he uses modes of criticism that are primarily psychological rather than intellectual in their mode of action. Competitions, explicit or implicit, within the class; the use of scorn, anger, and sarcasm to punish failure; the use of praise and often minor but important social privilege to reward success; all these are the daily fare of medical education. Their motive is the entirely honourable one of producing skilled practitioners of medicine who can use their knowledge of medical facts and their interrelations in conjunction with their physical skills to make sick folk better. In such a context the analytical and argumentative skills of the philosopher are not merely a luxury but also, it is sometimes said, a positive disadvantage. Doctors must make many practical decisions, often on the basis of inadequate information. Too finely developed a critical faculty endeavouring disinterestedly to learn the best that may be known and thought may positively inhibit the ability to make such decisions (pace Goethe who wrote "to act is so easy, to think is so hard").

Other factors militate against development of a strongly inquiring critical faculty in medical students-these become more obvious I think after the medical student has qualifiedwhen he has become, as it were, a soldier in the wards, certainly full of strange oaths, often bearded like the pard, usually jealous in honour, sudden and quick in quarrel, and seeking the 0 bubble reputation if not in the cannon's mouth then certainly in his boss's eye. The analogy between the young soldier in action ? and the intern is not too strained, I think, for my purpose. Both are fighting an enemy in the context of vigorously hierarchical organisations (the army and the hospital medical profession at the junior end). For both recognition of success (the bubble $\stackrel{\mathbb{\nabla}}{\circ}$ reputation) and promotion is in the disposition of their chiefs. Both are overwhelmed with the magnitude and urgency of the totally absorbing task at hand, and this thrusts away the tendency to reflect about its nature, propriety, and even perhaps about the 
best methods of performing it. Both have their instructions from further up in the hierarchy. Above all both are recently recruited members of ancient professions-professions that have firmly established traditions, attitudes, expectations, and esprit de corps.

\section{Psychologically acting criticism}

It is at this stage in our doctor's career that he is subjected to what is perhaps the most intensive period of psychologically acting criticism of his whole education. At the same time his own faculties of critical inquiry are vigorously discouraged, although self-criticism in the light of "the best that is known and thought in the world"-the world that is of the hospital medical profession-is equally vigorously encouraged. Part of all this criticism is orientated towards inculcating the right attitudes. It is in this emotionally supercharged stage of medical education that the role model and peer group pressures, if I may use the sociological jargon, work most strongly to affect his future medical attitudes. Some interesting support for this claim is afforded by Charles Bosk, an American sociologist who spent some 18 months living in the residents' mess with a group of junior surgeons-in-training. He participated in most of their activities, even assisting (he did not actually operate), and he observed the ways in which the attending surgeons (roughly the equivalent of our consultants) dealt with their juniors' errors. He points out that the errors that most concerned the attending surgeons were normative errors-that is, transgressions of certain moral norms such as hard work, honesty, thoroughness, self-criticism, and co-operation. The next most important type of error was what Bosk calls "quasinormative"-here the trainee transgressed the idiosyncratic requirements of a particular chief, despite acting in a way that would be fully approved by other chiefs. Bosk found that attending surgeons were far harsher in their responses to normative and quasi-normative errors than they were to technical errors, irrespective of the harm the latter may have inflicted upon specific patients. Their ways of dealing with normative errors almost always entailed hostility, expressed either in public or in the presence of members of the training group, and varying from a dressing-down to dismissal from the service or even the specialty. Technical errors on the other hand tended to be corrected with less aggression, more support, and more explanation. ${ }^{4}$ I suspect that Bosk's picture of his American teaching hospital accurately reflects the psychological pressures for conformity, especially for moral conformity, in many other hospital training environments.

Conformity to professional norms of behaviour is promoted by strong psychological pressures; self-criticism by the doctors in training on the basis of these norms is vigorously encouraged; and criticism of the norms themselves tends to be regarded as heretical and disloyal to the group and to the profession. As for overt criticism of their seniors by the juniors, this is almost totally inhibited by the powerful pressures of hierarchy.

\section{Professional moral or normative criticism}

So let us pass en to the justice of fair round belly with good capon lined, with eyes severe and beard of formal cut, full of wise saws and moral instances. Our medical equivalent is the professionally independent specialist-for instance the hospital consultant or the general practitioner principal. It seems that at this stage professional moral or normative criticism of, though not by, the doctor more or less stops. As Bosk says there seems to be an underlying assumption among teaching doctors that the rigorous normative controls of the training years must serve either to develop a powerful medical or surgical superego or else to exclude from the fraternity those in whom such a superego shows inadequate development. Thus it seems to be assumed that further normative criticism is largely superfluous and in any case unacceptable. Of course, it often will continue both as a result of the self-critical superego and also as a result of peer group pressure-for instance, through medical auditbut generally speaking only if the fully trained doctor decides that it shall continue. Meanwhile the latter may turn his critical attention to the doctor in training and to the medical student; he has been through the mill, now it is his turn to do a bit of milling.

As Bosk puts it, an attending surgeon "feels free to reprimand house officers as if they were children and often for no better reason than, 'I'm the boss and that's the way I want things done" "- for the house officer has not passed fully through the sets of rights, rituals, and ordeals that transform outsiders into insiders and make colleagues out of subordinates. But, Bosk continues, the crucial point is: "Once such a transformation occurs, a professional self is seen as something inviolable." Criticism may continue in scientific journals and other formal contexts; but such criticism can no longer be based on the emotional pressure-the crude emotional pressure-of pre- and rarely, I think, from the viewpoint of critical inquiry into the best tual pressure-on argument; and, I have suggested, for doctors the main intellectual pressure they have been trained to exercise is that of medical science; hence the main content of medical journals is medical science; intellectual criticism and inquiry concerning the mores, attitudes, and ethics of the profession is minimal.

I do not think I need pursue my hypothetical doctor further via lean and slippered pantaloonery to second childishness and mere oblivion (though in the past doctors at these late stages of professional development have occasionally indulged in lengthy disquisitions about medical mores, attitudes, and ethics though rarely, I think, from the viewpoint of critical inquiry into the best that may be known or thought. No, I think our imaginary doctor's story now is ended.

Where then has my analysis so far led me? In brief summary it has led me to suggest that the faculties of critical analysis common to the study of some of the humanities are importantly underdeveloped in medical education. In 1975 an editorial in the fournal of the Royal College of Physicians chided: "It has always been said that we are members of a learned profession. Learning encompasses a breadth of knowledge and curiosity. This is not so self-evident today." " As Sir Douglas Black, president of the Royal College of Physicians, put it more recently: "A doctor needs to be liberally as well as professionally educated. ..." But the doctor is not liberally educated, not "learned." Instead, learning propagated by psychologically rather than intellectually mediated criticism is the main method of instilling facts, skills, moral attitudes, and opinions into the trainee. Such critical faculties as are developed are largely those of the empirical scientist, and while these may well be adequate for the doctor to deal with the vast and constantly changing scientific and technical aspects of his work, they are not adequate to deal with the moral aspects of his workaspects that are also Protean and also changing. What I am not saying is that moral aspects of medical practice are ignored in the medical training. On the contrary, I have suggested that in the early professional stage they are heavily emphasised. They are emphasised, however, by the sort of criticism that seeks to propagate rather than to learn, and that seeks to propagate the best that is known or thought rather than the best that may be known or thought, to use the quasi-Arnoldian model I offered at the beginning. I have suggested that the same use of emotionally mediated criticism is also made for the scientific and technical aspects of medical training.

The trouble with this method is that it can as effectively propagate the bad, the indifferent, or the false as it can propagate the best and the true. In the scientific and technical aspects of medical practice the specialists and researchers in the relevant pure sciences are in constant touch with the practitioners and the teachers of medicine- - often indeed they are the same people. Thus the content of the scientific and technical education propagated in medical training is under constant analysis and revision, as is the content of the professional journals. Moreover, 
as I have said, the medical student himself is given some training in the methods of scientific criticism so that from his student days on into his professional independence he is equipped for intellectual criticism in the context of medical scientific papers in professional journals, of intraprofessional and interprofessional scientific discourse, and indeed of discussions with his patients about the scientific and technical aspects of medicine.

\section{Ethical analysis}

The moral attitudes and opinions promulgated via uncritical psychological pressures during medical training are not subject to such intellectual criticism, for the medical student and doctor is never given any training in ethical analysis, and the specialists in this field-the moral philosophers and indeed the moral theologians-neither teach medical students and doctors nor do they normally have access to the journals that doctors read. There are, of course, some exceptions to both these sweeping claims. An important one, if I may take this opportunity of saying so, is the London Medical Group, forerunner of medical groups throughout the country dedicated to discussion of medical ethics, and creator of the Society for the Study of Medical Ethics, which publishes the fournal of Medical Ethics (to which you are, incidentally, very welcome to subscribe).

The Society of Apothecaries is itself another exception in having contributed to this subject of study by establishing the diploma course in the philosophy of medicine. Nevertheless, all these organisations suffer from one vital defect-they nourish the spirit of philosophical and moral inquiry only in those students or doctors already sufficiently interested to attend their functions and read their publications. But medicomoral problems face every practising doctor, whether he is interested in them or not; and the opinions and attitudes inculcated by emotionally mediated criticism during his training are, on their own, simply inadequate to help him deal properly with such problems. Just as medical teachers are in close touch with the results of current inquiry in the pure sciences related to medicine, and sometimes are themselves active in such inquiry, so, I suggest, medical teachers should also be in touch with the results of current inquiry in moral philosophy, and sometimes perhaps be themselves concerned in such inquiry. Just as medical students are trained in the rudiments of scientific criticism and method, so I suggest they should be trained in the rudiments of moral philosophy and moral criticism. Both their general education as members of society and their professional education as practitioners necessarily concerned in moral decision-making in their everyday medical practice would surely benefit.

That all sounds very fine, but what practical difference would such an education make, it may be asked. The most important practical difference would be to enable doctors to distinguish moral from technical or scientific decisions. Ian Kennedy was surely exaggerating when he said that "each diagnosis is an ethical decision"? and probably exaggerating when he said that "the majority of decisions taken by doctors are not technical. They are instead moral and ethical." ${ }^{8}$ None the less, it is surely indisputable that a substantial part of medical practice concerns moral decision-making. The moral component, however, may not be apparent if the capacity for intellectual criticism has not been developed. Decisions to exclude as candidates for renal dialysis or transplantation people aged over 65 , or the mentally ill, or diabetics, or people who make burdensome claims on the social services are all at least in part moral decisions-they would only be merely technical or medical decisions if the "medical condition" of no one in these categories was ever improved by such treatment. Since this is not the case such decisions are in part moral evaluations of the form "it is not worth using our limited resources on people in these categories" or "our limited resources would be better used elsewhere."

But what is the practical advantage, the persistently sceptical opponent might ask, of distinguishing between the moral and the technical components of medical decisions? Various answers $\stackrel{\square}{?}$ suggest themselves. The first is that it enhances the doctor's and $\frac{7}{\mathrm{D}}$ the profession's self-respect, for it is simply ignorant to use $\varrho$ inappropriate criteria for decision making, and the criteria on

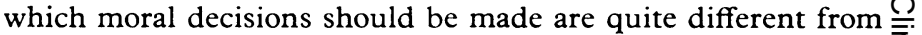
criteria on which technical decisions should be made. The second, instrumental, reason for making such distinctions is that making them and explaining them to the patient seems in $m$ practice to facilitate patients' ability to cope with what are often difficult decisions. For instance, my own clinical impression is that women who are unwillingly pregnant cope better with the $\stackrel{9}{\rightarrow}$ outcome, whatever it is, after they have discussed the various? moral components of the abortion debate. Certainly I have been thanked for provoking such discussions both by patients who $\frac{\bar{\sigma}}{\sigma}$ have continued with the pregnancy and by patients who have $\stackrel{\mathbb{Q}}{\varrho}$ had abortions. Doctors who discuss the moral issues with parents in the context of severely deformed newborn infants $\overrightarrow{0}$ also claim that the parents benefit from such discussion, whether the decision taken is to pursue energetic treatment or to with- $\vec{\omega}$ hold all except palliative treatment. ${ }^{9-11}$ (I cannot here enter the $\stackrel{D}{\circ}$ complex debate over whether decisions to withhold treatment $\frac{5}{3}$ in such cases can ever be justified on moral grounds, though for what it is worth I have no doubt that they can.)

Clinical impressions about benefit or anything else are, however, notoriously unreliable, and in any case the main reason for $\mathcal{O}$ distinguishing moral from technical decisions is, I believe, itself ${ }^{-}$ moral. It results from the moral claim that people should in general make their own moral decisions. It follows from this $\omega$ that doctors should not, in general, be making other people's moral decisions for them. That is the main reason for my belief $\overrightarrow{0}$ that doctors should be able to distinguish the moral from the technical components of their practice.

\section{Defence of medical elitism}

At this stage I must consider a point of view that has doubtless expressed itself among you and which runs vigorously counter to my theme. Medicine, it may be said, is an art as well as a science, a craft as well as a technology. While the scientific and technological aspects of medicine do require a rigorous intel- $\frac{\varnothing}{\varnothing}$ lectual education in which objective intellectual criticism is a necessary part, the art and craft of medicine do not require $\overrightarrow{0}$ intellectual critical ability-rather they need practice, apprenticeship-under the guidance of teachers who are skilled practitioners. Aristotle might be quoted, who says that "each man judges well the things he knows and of these he is a good judge. And so the man who has been educated in a subject is a good judge of that subject." 2

That is the principle on which our medical education in the art of medicine-which includes its moral components-is $\delta$ based. It is absurd to encourage criticism in the medical student $₹$ and young doctor-in-training, for he is not sufficiently educated 윽 in the subject to criticise usefully; even less useful are criticisms $N$ from outside the profession altogether, for these must be based even more on ignorance of medical practice. Patients, although $\frac{D}{0}$ they have a partial knowledge of their own medical predicament are not in a position to criticise or make decisions either, because their knowledge is so partial, in both senses of the term.

Because patients cannot fully understand the moral dimensions of their medical condition they are likely to make bado decisions from which doctors, who do understand their circum- $\mathbb{\Phi}$ stances, must protect them. Furthermore, such decisions are? often painful, and it is cruel and indeed immoral for the doctor $T$ to shed his own burden of responsibility on to the already laden $\stackrel{0}{\Phi}$ shoulders of his sick patient.

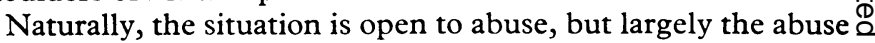
is avoided by the very same emotionally based criticism during training that your sociologist took 18 months to discover. Medicine is an ancient and noble profession dedicated to the well being of its patients. Its professional mores have been 
established over 2500 years with that well being as their primary objective, and in the full knowledge that deception and exploitation are particularly easy for the unscrupulous doctor. Read the Hippocratic Oath. The brain washing as you see it of the student and young doctor into acceptance of these professional mores is an honourable and intended effect of medical education, designed primarily if not entirely in the interests of the patient's well being. It is designed to protect those interests not by creating external checks and balances and other schemes for external scrutiny, all of which would not only impinge adversely on the therapeutic relationship between doctor and patient, but would also be easily evaded by the doctor intent to evade them.

Instead, the psychosocial pressures of criticism you have described create an internal set of checks and balances-what your sociologist called a medical or surgical superego. It is this that protects the interests of the patients, not your intellectually inquiring criticism of which you make so much, but which seems only to lead to unnecessary and inhibiting complexity, is incapable of any degree of scientific precision, and is characterised more by the disagreement of its practitioners than by any resolution of moral problems. No, it is the interaction of the experienced doctor, his developed medical superego, and the reality of his diverse clinical experience that results in the mature medical practitioner, who can then pass on his wisdom to the new generation of medical students and young doctors.

Although it is difficult to find such arguments in print, common as they are in practice, they are used to some extent by the late editor of the New England Fournal of Medicine in his George W Gay lecture "Arrogance" given at Harvard medical school. ${ }^{13}$ Among his themes were that "a certain amount of authoritarianism, paternalism, and domination are the essence of the physician's effectiveness." Arguing in favour of what he calls benevolent medical arrogance he suggests that it is cruel, undignified, and irresponsible to leave difficult decisions to patients. "The patient needs a physician from whom he will accept some domination. ... I do not want to be in the position of a shopper at the casbah who negotiates and haggles with the physician about what is best. ... I'll go further than that. A physician who merely spreads an array of vendibles in front of the patient and then says 'go ahead and choose, it's your life' is guilty of shirking his duty, if not of malpractice."

\section{Counterarguments to medical elitism}

Reeling back under my own and Dr Inglefinger's onslaughtI am sure that it reflects the views of some of my audience or their friends-let me try and reply on behalf of my original position against the view that I have just outlined and which I shall call the defence of medical elitism.

I agree that medicine is an art as well as a craft and a science and that the "practical wisdom" of this art/craft subsumes moral aspects of medical practice. I cannot agree, however, that these moral aspects do not need intellectual criticism nor that doctors are the proper people, in general, to take moral decisions on behalf of their patients. Let me analyse the argument that supports the medical elitist's case.

The claim that, roughly speaking, doctors must be trained to behave morally rather than educated to argue the hind legs off a donkey is of fundamental importance, and too often I believe ignored by philosophers. Certainly the various psychological pressures used "to propagate the best" may be an essential part of people's moral training. My point, however, is that while such training may be necessary, it is not sufficient and must be complemented by an education that includes intellectual criticism of the very moral standards that are being propagated.

The first reason for this assertion is that we live in a morally transitional society-in the midst of what one might describe as postreligious presecular pluralism! In such circumstances even doctors who are certain of the validity of their own moral stance, and who believe that it is their responsibility to impose this moral stance on their patients, must be able to justify their beliefs to patients, to other doctors, and to society at large, if they are to get away with it. Yet to be able to justify their moral claims such doctors simply must be able to reason coherently both in their own defence and in rejection of any competing claims that they are prepared to over-ride. So, for purely pragmatic reasons today's doctor, especially if he is a medical elitist, must not only be trained to behave morally, he must also be educated in critical moral analysis.

This pragmatic point serves to highlight a more important moral claim concerning the insufficiency of mere moral training: while it may be acceptable to teach young children to do this or that "because I told you so," adults who continue to behave according to someone else's moral rules without having criticised them-without having tested them against competing alternatives-have not grown up morally; they have not become fully autonomous moral agents. For this one requires not only training to behave well (one might train a dog or a robot to behave well) but also the disposition to choose between alternative courses of action on the basis of moral reasoning; reasoning which can detect and reject prejudice and invalid argument, which can defend the reasoner's own moral position, and which yet can recognise the strengths as well as the weaknesses of the moral positions of others. But this all requires intellectual criticism carried out in a "disinterested endeavour to learn and or to propagate the best that is or may be known or thought in the world."

Thus the first counterargument of the medical elitist-that moral training is sufficient and that intellectual moral criticism is unnecessary in medical education-fails.

His fallback position is that while intellectual criticism may be necessary, only fully trained doctors can properly criticise in medical ethics. Aristotle's remark that the man who has been educated in a subject is a good judge of that subject would support this claim only if it were $(a)$ true that doctors are educated in medical ethics-I have been arguing that they are not, and the elitist is arguing that they don't have to be-and $(b)$ true that only experienced doctors can be educated in medical ethics. This idea, often supported by the claim that only experienced doctors can understand the problems of medical ethics, and that patients, students, younger doctors, moral philosophers, and hoi polloi in general cannot comprehend these problems, is simply the hubris of ignorance.

They may be complicated by technical medical problems, but essentially the moral problems of medical practice are no different from any other sort of moral problem. There is considerable confusion among many doctors on this point - they tend, because they have been trained to do so, to transmute moral problems into technical problems-but separate out the practical and the technical from the moral aspects of medical practice and it is simply false to state that non-doctors cannot understand the latter. On the other hand, it may certainly be true that they cannot understand the medical and technical aspects of some medicomoral problems without help from people who do. This is a very real problem in medical ethics, but it seems to me to entail no more than the need for interdisciplinary co-operation in its study. If they try doctors are perfectly capable of explaining and making comprehensible to non-doctors the technical aspects of their practice; if they try they are also perfectly capable of quite wonderful obfuscation.

\section{Scientific precision}

What about the criticisms that moral philosophy leads to unnecessary and inhibiting complexity, is characterised by disagreement about, rather than resolution of, moral problems, and is incapable of any degree of scientific precision?

To take the last point first, let me quote Aristotle again: "It is the mark of the educated man to look for precision in each class of things just so far as the nature of the subject admits" he 
writes at the beginning of the Nichomachean Ethics, ${ }^{14}$ and ethical reasoning does not admit of scientific precision. It is a manifestation of their inadequate critical training that doctors and scientists could feel able to criticise ethics for being incapable of scientific precision, a criticism which, to jump a couple of thousand years, Gilbert Ryle would have said embodied a category mistake.

As for moral disagreement, certainly moral reasoning may result in it. Again, it is the result of an inadequate critical training to assume that moral problems all have a single correct answer like some arithmetical problem. But although moral disagreement is unavoidable, there is a very important moral difference between moral disagreement resulting from valid argument based on different premises, themselves parts of coherent networks of moral beliefs, and moral differences based on faulty or inadequate reasoning, prejudice, inconsistency, incoherent basic beliefs, and so on. Part of moral analysis involves eliminating such undesirable components of moral decision making. A further part concerns how best to resolve the residual moral disagreements.

Finally, it can surely be no defence for excluding criticial analysis of moral problems that this sometimes demonstrates a moral problem to have more complexity than was previously believed. My contention is that doctors should be taught to recognise the moral components of their work, to analyse at least at basic level the issues to be decided, and to know the various standard moral positions on these issues. If this results in a more complex assessment than ignorance and prejudice results in, so be it. So does medical education in general. I am not advocating that every doctor should be a professional moral philosopher or theologian. I am simply advocating that just as all doctors, whatever their specialty, are expected to know the rudiments of scientific and technical medical practice across the board, so too they should know the rudiments of moral philosophy, the foundation of which is critical analysis. In addition I have suggested that professional links should be maintained between practising doctors and experts in moral philosophy just as links are maintained with experts in the basic sciences. Finally, I have suggested that some practising doctors should develop a skill in moral philosophy over and above the basic skills that all doctors require, just as some practising clinicians maintain a skill in one of the medical sciences. Why shouldn't six months or a year studying medical ethics be an acceptable component of interested doctors' professional training?

\section{Golden guardians}

Before considering the medical elitist's remaining arguments let me offer a Platonic parallel-and parable. Plato too was a moral elitist, and in his Republic ${ }^{15}$ he described a, for him, Utopian society in which important moral decisions would be taken by educated experts on behalf of the rest of the population. Like our medical elitists these golden guardians would make their moral decisions on behalf of others with the purest of intentions-notably the well being of all the people in their charge. The decisions would have to be mandatory and enforced by punishment if necessary, and there would be no sharing of these decisions with the people affected by them-for they would not have been trained to understand moral problems. The scope of the moral decisions to be made by the guardians would be wide-it would include eugenic selection of spouses, compulsory contraception, abortion and infanticide, compulsory separation of children from their parents, and communal sharing of all property. Lying by the guardians to the workers would be quite in order if this were in the workers' interestsfor example, the marriages arranged on eugenic grounds would be ostensibly arranged by lotteries while actually being rigged to produce the required results. In this way the workers would not be upset by knowing the truth. Another "noble lie" as Plato calls them would explain to the workers why they had been chosen for their roles. The real reason was their inferior intelligence, but they would be told it was because the Gods moulded everyone before birth with either gold in their souls to be guardians, or with silver in their souls to be soldiers, or with bronze in their souls to be workers.

Repugnant as I trust you find this Platonic Utopia to be-the case against it is argued pungently by Karl Popper ${ }^{16}$-and analogous in many ways as it is to the medical elitist position Im sketched earlier, there is in Plato's vision a clear requirement? that the guardians, if they are to be entrusted with the moral guidance of others, must have a long and intensive education, part of which would include moral philosophy. Plato gives anc extensive account of this education, which is primarily aimed at an understanding of the Forms, the Form of the Good being? the highest of all, and the ideal to which mankind must properly aspire. Such an understanding would be possible for only a tinyos minority of society, but rigorous selection, education, and $\overrightarrow{0}$ training of this elite few would ensure the elimination of their ${ }_{-}$ ordinary human tendencies to act corruptly or with self-interest, $\overrightarrow{\vec{\omega}}$ and their knowledge of the Form of the Good would ensure that $\stackrel{\circ}{ }$ the moral decisions they took on behalf of others would be the right ones.

Those who find all this merely an additional reason for sup- $-\omega^{\infty}$ porting the defence of medical elitism-why it even has theo authoritative backing of Plato-must surely agree with PlatoO that if moral decision-making on behalf of others-their patients. -is to be the prerogative of the medical profession, then the medical profession must show itself to have some special ${ }^{\omega}$ expertise not merely in the technical and scientific skills but, like Plato's guardians, in the making of moral decisions. They $\overrightarrow{0}$ will surely not claim that this is currently the case-those whor would should recall Granada Television's 1980 series on medical ethics, in which members of the medical profession, some highly experienced, were given some exercises in ethicalo reasoning. Tricky as the circumstances and the questioners ${ }^{-}$ were, selective as was the final screened version, still I doubt if $\overrightarrow{0}$ many of the participants would have met Plato's requirements. of excellence in moral philosophy. Yet particularly for those whoס advocate the medical elitist position is not such an excellences essential ? If doctors are to take sole responsibility for making moral decisions on behalf of, and in the best interests of, theiro patients do they not have even greater a responsibility than otherwise to educate themselves in the principles of moral philosophy?

My belief is that the more they do study moral philosophy the less inclined will such doctors be to accept the medical elitism which, I hope I have shown, should have led them to such study.

\section{Personal autonomy}

My main reason for my belief is that once you undertake even elementary studies in moral philosophy you rapidly realise how difficult it is to sustain any moral theory that does not assumen that, at least prima facie, everyone has the essential responsi $\rightarrow$ bility and right to make his own moral decisions. That is parto of what we mean by autonomy; autonomy is an essential aspect of being a moral agent, and people are essentially moral agents I cannot argue for these substantive claims in moral philosophy now, but even at an intuitive level I imagine that many of your would accept them as being true. Accepting their truth is however, incompatible with accepting the thesis that I have dubbed medical elitism, or its Platonic forerunner. The reason ${ }^{+}$ clearly is that both of these positions arrogate the power of moral authority to an elite few, thus withdrawing mora autonomy from those people on whose behalf the elite make moral decisions. There is no need to impugn the motives of the elitists, which are often-perhaps usually-impeccably honour able. The elitists wish to do the best on behalf of their fellow citizens in Plato's case, their patients in the case of those whe support medical elitism. But to act as they propose is necessarilyo 
to withdraw autonomy from those on whose behalf they so act.

It is in this context of the importance of personal autonomy that I wish to consider the remaining arguments of the medical elitist. These are $(a)$ that patients want and expect their doctors to take responsibility for their whole "case" and make all medical, including medicoethical, decisions; $(b)$ that it is cruel and irresponsible to add difficult moral decisions to sick patients' existing burden of disease; and $(c)$ that if left to make their own medicomoral decisions most or many people would make bad moral decisions, and it is the doctor's responsibility to protect his patients from such bad decisions.

The first argument rests on the implied premise that the doctor should do what the patient wants him or her to do, with which I agree. Some patients undoubtedly do wish their doctors to take all decisions, moral as well as technical. Some undoubtedly do not. As long as patients are given genuine encouragement to indicate which in particular circumstances they do want, their autonomy is being respected. Presupposing that doctors should make the moral decisions is not respecting people's autonomy. It is true that sometimes medicomoral decisions are anguishing -but this is usually because the available alternatives from which a choice must be made are all anguishing. The only way the anguish can be avoided is for the patient to be unaware of any of them-and this usually entails deceiving the patient. Apart from the practical problems that this often entails-oh what a tangled web we weave, etc-apart from the burden of dishonesty that this often imposes on relatives, and apart from the denial of autonomy to the patient, such deceit may not save the patient any anguish, and indeed may positively increase his anguish. A patient dying from an inoperable and highly malignant stomach cancer may prefer to have radiotherapy despite the small chance of its success on the grounds that he would prefer something to be done than nothing. On the other hand, he may prefer to leave hospital, settle his affairs, and die without the additional discomfort of radiotherapy. In the latter case if such a patient discovers before he dies that he has been deceived his final anguish may be far greater than that which discussion of the alternatives would have produced. Finding out what patients really want is extremely difficult without giving the game away. I have often wondered if it would not be possible to ask all patients before they go into hospital, perhaps on a questionnaire along with questions about their religion, whether they would want to be told bad news or would rather it were kept from them; whether they would want their doctors to discuss with them moral decisions that might arise in their treatment or whether they would prefer their doctors to take such decisions for them. Certainly a pilot investigation along these lines is likely to be snapped up by the Fournal of Medical Ethics! Once again if patients are given a genuine opportunity to indicate their preferences their autonomy is respected; but the doctrine of medical elitism forecloses their options and denies their autonomy.

Finally, there is the claim that doctors tend to make better medicomoral decisions than their patients. This is really the paradigm claim of the elitist position. Needless to say there are powerful facts of human life which lead people to make it. People who are used to dealing with a class of problems often do deal with them better than people who are not. People who are sick often are not on their optimal problem-solving form. Non-doctors may find it more difficult to sort out the various strands, medical, technical, and moral, of their predicament, than doctors. Then there remain social structures in which doctors are expected to run the show and patients to do what they are told. Hospitals, particularly, tend to infantilise their patients, and it is usual and probably correct to keep the moral autonomy of infants in careful parental control. At some stage, however, parental control must be relinquished as infants develop into morally independent agents. Adult patients are not infants; they are morally independent agents-as such they have the right to make their own moral decisions if they choose to do so, even if those decisions are bad ones. It is true that some people do not take their moral autonomy seriously and make their moral decisions without sufficient thought or comprehension. That, however, is their prerogative. For the doctor who accepts this and rejects medical elitism this may all entail considerable efforts to explain the technical and the moral implications of the patient's position and alternative courses of action. The decisions, however, he will encourage the patient to take, only taking them himself if it is clear that this is what his patient wishes.

Finally, if doctors are unconvinced about the importance of patients' moral autonomy let them consider, apart from Plato's Republic, their own reactions if another doctor were to make a moral decision on their behalf of which they strongly disapproved. If their autonomy should be respected, so should everyone's.

I have argued-and Plato would agree!-that the doctor who believes in what I have called medical elitism is properly bound to educate himself in moral philosophy. If it is true that in circumstances where a medical decision entails a moral decision a doctor who rejects medical elitism has some responsibility to indicate this to his patient, to indicate the nature of the moral problem to his patient, and perhaps even to help him understand the various ways in which the problem may be assessed, before the patient makes his own moral decision, then once again such a doctor is bound to educate himself in the principles of moral analysis. In either case, then, doctors need some education in the analysis of moral problems, which is another way of saying that they need to know some moral philosophy.

Moral philosophy entails moral analysis-a form of nonscientific inquiring intellectual criticism that requires from all its participants "a disinterested endeavour to learn and or propagate the best that is or may be known and thought in the world."

It should also provide a welcome additional and different intellectual stimulus in medical education, lighter on the rein than many. And it should, to give Matthew Arnold the last and unmodified word, perform "the best spiritual work [of criticism] which is to keep man from a self-satisfaction which is retarding and vulgarising, to lead him towards perfection by making his mind dwell upon what is excellent in itself. ..."

But perhaps there are those who would prefer me to end with Caterina's opinion of criticism in George Eliot's Scenes of Clerical Life: "Animals are such agreeable friends-they ask no questions, they pass no criticism."17

\section{References}

1 Arnold M. The function of criticism at the present time. In: Essays in criticism: first series. London: Macmillan, 1928:38.

2 Shakespeare W. As you like it. Act 2, scene 7.

${ }_{3}^{3}$ Popper KR. Conjectures and refutations. London: Routledge and Kegan Paul, 1974:33-65 and passim.

${ }^{1}$ Bosk CL. Forgive and remember-managing medical failure. Chicago and London: The University of Chicago Press, 1979.

"Anonymous. F R Coll Physicians 1975;10:4.

${ }^{6}$ Black D. Many parts. In: Green College Lectures, 1981. Health and Sociely. Oxford: Green College, 1981:32.

7 Kennedy I. The rhetoric of medicine. Lecture 1 (5 November 1980) of the 1980 Reith lectures "Unmasking medicine." Listener 1980 Nov 6.

${ }^{8}$ Kennedy I. If I were you Mrs B. Lecture 4 (26 November 1980) of the Reith lectures "Unmasking medicine." Listener 1980 Nov 27.

${ }^{9}$ Duff RS, Campbell AGM. Moral and ethical dilemmas in the special care nursery. N Engl f Med 1973;289:890-4.

1) Ellis HL. Parental involvement in the decision to treat spina bifida cystica. Br Med F 1974 ;i:369-72.

11 Campbell AGM, Duff RS. Deciding the care of severely malformed or dying infants. Fournal of Medical Ethics 1979;5:65-7.

12 Aristotle. Nichomachean ethics. 1094b29.

13 Ingelfinger FJ. Arrogance. N Engl f Med 1980;303:1507-11.

14 Aristotle. Nichomachean ethics. 1094b29.

15 Plato. Republic.

16 Popper KR. The open society and its enemies. Vol 1. Plato. London: Routledge and Kegan Paul, 1974.

17 Eliot G. Mr Gilfill's love story. In: Scenes of clerical life. London: Penguin English Library, 1980:181.

(Accepted 5 August 1981) 